\title{
Detection of intraword and interword letter repetition: A test of the word unitization hypothesis
}

\author{
LESTER E. KRUEGER \\ Ohio State University, Columbus, Ohio
}

\begin{abstract}
Do words, as familiar units or gestalts, tend to swallow up and conceal their letter components (Pillsbury, 1897)? Letters typically are detected faster and more accurately in words than in nonwords (i.e., scrambled collections of letters), and in more frequent words than in less frequent words. However, a word advantage at encoding, where the representation of the string is formed, might compensate for, and thus mask, a word disadvantage at decoding and comparison, where the component letters of the representation are accessed and compared with the target letter. To better reveal any such word disadvantage, a task was used in this study that increased the amount of letter processing. Subjects judged whether a letter was repeated within a six-letter word or a nonword (Experiment 1; intraword letter repetition) or was repeated between two adjacent unrelated six-letter words or nonwords (Experiment 2; interword letter repetition). Contrary to Pillsbury's word unitization hypothesis, both types of letter repetition (intraword and interword) were detected faster and just as accurately with words as with nonwords. In Experiment 2, however, interword letter repetition was detected less accurately on common words (but not on rare words or third-order pseudowords) than on the corresponding nonwords. Thus, although the familiar word does not deny access to its own component letters, it does make their comparison with letters from other words more difficult.
\end{abstract}

Do words reveal or conceal their component letters? Some authors have argued that the word, as a familiar unit or gestalt, ought to conceal its letters. According to Pillsbury (1897), in a brief presentation of a word, "the rush of recognition may be so violent that the letters themselves are entirely neglected-forgotten, or not seen at all" (p. 378). Thus, the word may tend to overshadow or swallow up its letter components.

Letters need not be seen at all if words are recognized or encoded in a holistic manner, that is, "on the basis of supraletter features from units larger than the letter" (Proctor \& Healy, 1985, p. 287). Besner, Davelaar, Alcott, and Parry (1984) reviewed the evidence and concluded that the single word is not recognized on the basis of transletter features or the outline shape of the word: "letter recognition is ... a necessary preliminary to word recognition" (p. 132). But even if "with highly familiar words such as the or and, identification often can occur at the word level prior to complete letter identification" (Proctor \& Healy, 1985, p. 287), that would not necessarily block or retard subsequent access to the letter contents, which is the key issue here. "The crucial assumption of the unitization hypotheses ... is that once a larger unit is identified, the processing of its component letter units stops, even if the letters have not yet been identi-

The author is grateful to Philip A. Allen and Alice F. Healy for helpful comments on an earlier version of this report. Requests for reprints should be sent to Lester E. Krueger, Human Performance Center, Ohio State University, 404-B West 17th Avenue, Columbus, OH 43210-1285. fied"' (Healy, Oliver, \& McNamara, 1987, p. 280). According to the strong version of the word unitization hypothesis (Pillsbury, 1897), the word representation always or necessarily resists revealing its letter components. According to the weak version of the hypothesis, certain additional conditions, such as the presence of adjacent words (Healy et al., 1987), are necessary if the recognition of a word is to hinder access to its letter components. As discussed below, much evidence indicates that word unitization can indeed be induced by various conditions, thus supporting the weak version of the hypothesis. However, no clear-cut evidence favors Pillsbury's strong version, perhaps because a large word advantage at one stage (encoding) masks a word disadvantage at another stage (decoding and comparison). The present study attempted to make a further, more sensitive test of the strong version of the word unitization hypothesis.

\section{Single-Word and Multiword Studies}

Contrary to Pillsbury's (1897) hypothesis, letter detection typically is faster and/or more accurate when a single word rather than a nonword is shown (Henderson, 1975; Krueger, 1975). However, Lawry (1980) found that a lowercase letter designated by a vertical arrow marker was identified as accurately, and significantly more rapidly, when it appeared as part of a nonword rather than a word. However, Lawry assigned several letters to the same response set, and constrained the random permutation of letters in the nonwords so that a letter flanking the target was sometimes compatible and sometimes in- 
compatible with the target (i.e., belonged to the same or opposite response set). Thus, in the vicinity of the target letter, the nonwords may have been nearly as regular or sequentially redundant as the words.

Although single words typically reveal rather than conceal their component letters (Henderson, 1975; Krueger, 1975), attempts to demonstrate a similar familiarity benefit for words with displays containing several words or nonwords have produced mixed results. Krueger (Greenberg \& Krueger, 1983; Krueger, 1970, 1982) found that letter search was faster through sentences than scrambled prose and through arrays of words than arrays of nonwords, and Levy (1983; Levy \& Begin, 1984; Levy, Newell, Snyder, \& Timmins, 1986) found that misspellings were better detected in familiar than unfamiliar texts. However, Healy (Drewnowski \& Healy, 1977; Healy, 1976, 1980; Healy \& Drewnowski, 1983) and Schindler (1978) reported cases in which target letters were less readily detected when embedded in more familiar words or contexts. ${ }^{1}$ In the latter studies, more errors of omission in letter detection occurred on highfrequency than on low-frequency words (word frequency disadvantage) and on correctly spelled than on misspelled words (word-inferiority effect). The effect is enhanced when the test words occur within a meaningful context (Drewnowski \& Healy, 1977), but it also occurs with scrambled text (Healy, 1976). Healy (1976; also see Drewnowski \& Healy, 1977; Schindler, 1978) found that constituent letters are more poorly detected in function words, such as the, than in content words, owing presumably to the greater familiarity of function words. This effect is dependent on the availability of a word-level unit that is consistent with the letter string, according to Healy (1980), who found no difference in the detection of misspelled function and content words.

Healy et al. (1987) found that the number of words in view at any instant is critical. A word-inferiority effect and a word frequency disadvantage were consistently obtained when two to four words were shown at a time, but not when one word was shown at a time. Healy et al. argued that as more words become visible, the "pull" of the text (i.e., the compulsion to move ahead to the next word once the current word is identified) disrupts letter detection in familiar words. If a single word is shown, then there is no compulsion to move ahead, and the word and the letters it contains will continue to be processed even after the word has been recognized. Thus, Healy et al.'s results contradict the strong version of the word unitization hypothesis (Pillsbury, 1897), according to which the word, once recognized, always or necessarily hinders the subsequent decoding of its letter components. ${ }^{2}$ Healy et al. told subjects to read a passage at their "normal reading speed,' and to circle the letter $t$ whenever they came to it. These instructions seemingly did not permit subjects to pause after each word was encoded in order to decode its constituent letters. Thus, in their task, the text may have performed a kind of cognitive masking, as it were, in which the presence of an adjacent word or phrase produced specific interference with the full processing of a word. ${ }^{3}$ O'Hara (1980; O'Hara \& Eriksen, 1979) found that an extraneous trigram, placed between two letters that had to be compared, interfered less with the detection of a match between the two letters when it was a word than when it was a nonword, presumably because as a word it could be encoded as a single unit rather than as a set of letters. Here, too, task demands and conditions favored not decoding the component letters of the word. Likewise, when treating the letter string as a whole could improve performance (via redundancy gain), Silverman (1976) found that words were processed as integral stimuli, and nonwords or consonant strings as separable stimuli; however, when the task required filtering out the other letters and attending only to the first letter, Silverman (1977) found performance to be no worse on words than on nonwords (see also Krueger \& Shapiro, 1980 ), which "suggests that visually presented onesyllable words are not integral stimuli" (p. 104). Greenberg and Krueger (1983) presented several intact words at a time (upright, preview condition), but required an overt response to each individual word, which may explain why they found a word advantage on response time (RT) with a multiword display.

\section{A Processing Model}

The studies reviewed above may have provided no clear-cut support for Pillsbury's (1897) word unitization hypothesis because the word both helps and hurts letter detection, with the benefit typically outweighing the cost. If the cost could somehow be magnified, that would more clearly reveal its presence. In letter detection, there are two main stages or processes: (1) encoding and (2) decoding and memory comparison. In encoding, the basic representation of the word or nonword is formed and is placed in working memory (perceptual synthesis). In decoding and memory comparison, the letter components of that representation are accessed and compared with the target letter in memory (postperceptual analysis).

Johnson $(1977,1981)$ postulated that, when presented with a word or a nonword, a person would first attempt to encode the string as a unit. The attempt would succeed with a word, but not with a nonword (i.e., a scrambled collection of letters), which would then be parsed and its letters encoded. However, letter search might still be faster and/or more accurate with a word than with a nonword, because the perceiver might readily do a memory search of the component letters of the word (Johnson, 1986); that is, the holistic representation of the word in memory might readily be converted or parsed into its component letters. The role of such decoding and memory comparison may be magnified by increasing the number of target letters, so that the subject searches for two or three target letters on some trials, rather than only one. If familiarity aids memory search, then the word advantage ought to be larger with the larger target set. However, under normal conditions, the time savings for familiar (word; upright letter) displays is nearly constant, regard- 
less of the size of the target set (Greenberg \& Krueger, 1983; Krueger, 1970, 1982). This indicates that familiarity aids only encoding. Johnson (1986) found that the time savings for words in a letter-search task increased as the length of the word and nonword strings increased, which suggests that the decoding and comparison process was faster for words than for nonwords. However, given the greater sequential redundancy and distinctiveness of the longer words, the greater time savings for them may be due to an enhanced word advantage at encoding, rather than at decoding or comparison.

There may, in fact, be a word disadvantage at decoding and comparison. With unpracticed subjects and under difficult conditions, as the number of target letters increases, the time savings for the words does not remain constant, but decreases (Greenberg \& Krueger, 1983; Krueger, 1969). Even under more favorable conditions, Krueger (1982) found that the time savings per six-letter word, although nearly constant, was somewhat larger when the target-set size was one $(98 \mathrm{msec})$ rather than two $(73 \mathrm{msec})$ or three $(65 \mathrm{msec})$. However, the decrease in the time savings for words with increased target-set size may be due not to word unitization (i.e., less efficient decoding or comparison with words), but to the strain that the greater memory load of the larger target set puts on the encoding of words. Furthermore, by emphasizing processing at the letter level, the larger target set may have encouraged subjects to process the words as collections of letters rather than as familiar strings or whole words.

The task used in the present study magnified the decoding and comparison process, but without thereby increasing the memory load. In Experiment 1, subjects had simply to decide whether a letter appeared twice within the same six-letter word (e.g., FREDDY) or nonword (e.g., WSAEEN). The memory load thus was zero, since there were no predesignated target letters. If decoding or comparison is significantly more difficult for words than for nonwords, then the word-superiority effect ought to be eliminated or possibly even reversed in the present study, since the cost at decoding and comparison would approach or exceed the benefit at encoding. If there is no cost at decoding or comparison, and if words are still processed as familiar strings, however, then the typical wordsuperiority effect ought to be found here.

More decoding and comparison was necessary in the present study when no letter repetition was present, and thus every possible letter combination had to be examined; on letter repetition displays, subjects could (and did) selfterminate processing as soon as the repetition was detected. Thus, any loss or reversal in the word-superiority effect owing to more difficult decoding or comparison of words ought to be especially evident on no-repetition trials.

Experiment 2 tested whether the word-superiority effect would be lost or reversed when the comparison is not within a single word or nonword, but between two unrelated six-letter words or nonwords, which may or may not contain the same letter (e.g., INFORM ADVICE). Even if individual words are readily decomposed into their component letters (Experiment 1), there may be a sharp demarcation or segregation of letter sets from different words, so that the comparison of letters between two unrelated words is more difficult than that between two nonwords.

\section{EXPERIMENT 1}

In Experiment 1, a single, six-letter word or nonword was presented, and subjects had to judge whether two of its letters were identical. Letters in the first two serial positions ( 1 and 2 ) or in the last two positions (5 and 6) never were identical, but all other pairs of serial positions were used to present identical letters, and with equal frequency. On half of the trials, the word or nonword contained no repeated letters. The words on the no-repetition trials were classified by frequency of occurrence in English. Thus, Experiment 1 could detect a word frequency disadvantage, as well as a word-inferiority effect.

Pilot tests indicated that the letter repetition, unless it involved adjacent positions, was quite difficult to detect, owing apparently to lack of structure in the stimulus that would permit a systematic and exhaustive comparison of all possible pairs of letters. To test this conjecture, on half of the trials, a blank space or gap was inserted in the middle of the word or nonword, thus dividing it into two threeletter segments. With the gap, subjects could compare all possible pairs within each of the two segments, and then compare each letter in one segment with the set of letters in the other segment. Therefore, performance in the gap condition was expected to exceed that in the even-spacing condition. The gap also was expected to hinder word unitization, and thus attenuate any word-inferiority effect obtained. If a word-superiority effect occurred instead, then that, too, ought to be attenuated in the gap condition, owing, again, to the greater difficulty in processing the word as a familiar string.

\section{Method}

Subjects. Twenty Ohio State University undergraduates participated in order to receive credit in an introductory psychology course. Data were excluded on 4 additional subjects whose errors exceeded $10 \%$. All subjects had at least $20 / 30$ vision (corrected) as tested with a Snellen chart.

Apparatus. Uppercase letters were presented at a $60-\mathrm{Hz}$ refresh rate and at $32 \mathrm{~cd} / \mathrm{m}^{2}$ intensity on a greenish-tint, fastdecay P31 phosphor (decay to $1 \%$ intensity at .25 msec after display offset) by an Imlac PDS-4 graphics computer, which measured RT to an accuracy of $1 \mathrm{msec}$. The letters, presented as thin, illuminated lines on a dark screen, were software generated, using short line vectors, so as to resemble normal English uppercase letters. Each subject sat alone in a dark room, with his/her head held fast in a chinrest located $70 \mathrm{~cm}$ from the display screen.

Stimulus materials. Each letter was $.29 \mathrm{~cm}$ wide and $.43 \mathrm{~cm}$ high, and $.19 \mathrm{~cm}$ separated adjacent letters. The six-letter display thus was $2.69 \mathrm{~cm}\left(2.20^{\circ}\right)$ wide with even spacing and 
$3.17 \mathrm{~cm}\left(2.60^{\circ}\right)$ wide when a blank character or gap was inserted between the third and fourth letters. The display was centered $0.3 \mathrm{~mm}$ above a small $(1.6 \times 1.6 \mathrm{~mm})$ plus sign, which was the fixation mark at the center of the screen.

The 260 words and 260 nonwords shown on the regular trials were devised as follows. Ten instances each of words having the following 13 pairs of serial positions of repeated letters were obtained, for a total of 130 words: 1,$3 ; 1,4 ; 1,5 ; 1,6 ; 2,3 ; 2,4$; 2,$5 ; 2,6 ; 3,4 ; 3,5 ; 3,6 ; 4,5 ; 4,6$. (Excluded were the 1,2 and 5,6 pairs, for which there were too few instances. It should be noted that by excluding both pairs of extreme positions, symmetry in the distribution of locations of repetition was preserved.) The words for a given set were obtained by starting with the most frequent words in Kucera and Francis's (1967) word count, and working down the list until the 10 words needed had been obtained. (Excluded were words that were very similar to words already obtained, or that would produce an overuse of a particular repeated letter.) For the no-repetition trials, 130 words were similarly obtained. These words, whose frequency of occurrence covered approximately the same range as that of the words containing letter repetitions, were divided into 13 sets of 10 words each, based on frequency of occurrence. The range of frequency of occurrence per million words of printed American English for each list is given in Tables 2 and 3 . The frequency of occurrence of most words exceeded 50 per million.

For each set of 10 words, the 10 corresponding nonwords were devised by randomly permuting the letters within each of the four or six nonrepeated positions, with the constraint that no additional letter repetition thereby result, that no real word be formed, and that the number of vocalic letters (A, E, I, O, U, and $Y$ ) in each nonword be equal to that of one of the words. Thus, in the case of letter repetition trials, the 10 nonwords had the same repeated letters in the same serial positions as the corresponding 10 words. Five of the 10 words or nonwords in each set were randomly assigned to the gap condition, and the other 5 to the even-spacing condition. The 130 words and 130 nonwords in each spacing condition (gap, even spacing) were randomly intermixed and presented in 10 blocks of 26 trials each, and the 20 blocks for both spacing conditions were randomly intermingled. Four practice trials preceded each block, and there was an initial practice block (intermixed gap and even spacing), for a total of $\mathbf{6 3 0}$ trials. Additional words and nonwords were devised for the 110 practice trials, so each of the 520 regular items was used once and only once during the session. Four different random orderings of blocks and the pairs within spacing conditions were used.

Procedure. On each trial, the fixation mark appeared alone for $.5 \mathrm{sec}$. The word or nonword then appeared just above the fixation mark until a response was made. No feedback was given on the accuracy of the response during the .5-sec interval between trials. During the 10-sec interval between blocks, the next series of trials was read in from the host computer. The subjects were instructed to respond as rapidly as possible without sacrificing accuracy.

Ten subjects pressed a right-hand button if a letter was repeated and a left-hand button if all six letters were different, and the other 10 had the reverse hand assignment. Trials with an RT greater than $10 \mathrm{sec}$ or less than $200 \mathrm{msec}$ were to be discarded prior to data analysis, but no trial so qualified, so none was discarded. Mean RT was computed for correct trials only. The standard error $(S E)$ of the difference is reported for factors having two levels, and the mean-squares error (MSe) term is reported for factors having more than two levels.

\section{Results}

The main analysis examined the effects of item type (words vs. nonwords), gap (present vs. absent), and repetition (present vs. absent), all of which are within-subjects factors. As shown in Table 1 , intraword letter repetition greatly decreased RT compared with no repetition $[F(1,19)=71.99, p<.001, S E=60.76]$, but increased errors $[F(1,19)=115.12, p<.001, S E=0.667]$. Thus, subjects self-terminated processing as soon as letter repetition was detected, but often made misses (i.e., failed to detect the letter repetition).

Mean RT was lower for words than nonwords $[F(1,19)$ $=20.16, p<.001, S E=21.47$ ], especially when there was no gap $[F(1,19)=5.17, p<.05, S E=10.87$, for the item type $\times$ gap interaction on RT]. The gap mainly reduced the word advantage when there was no letter repetition $[F(1,19)=4.35, p \approx .05, S E=8.79$, for the item type $\times$ gap $\times$ repetition interaction on $R T]$. Errors did not differ between words and nonwords $(F<1)$, but misses were relatively more frequent on nonwords, whereas false-positives were relatively more frequent on words $[F(1,19)=5.89, p<.05, S E=0.382$, for the item type $\times$ repetition interaction on errors]. Compared with even spacing, the presence of a gap increased RT $[F(1,19)=26.94, p<.001, S E=18.74\}$ and produced relatively more misses $[F(1,19)=6.91, p<.025$, $S E=0.437$, for the gap $\times$ repetition interaction on errors], but increased errors very little, and nonsignificantly, in general $[F(1,19)=1.03, S E=0.411]$.

A second analysis, which was restricted to letter repetition trials, examined the effects of repetition location, item type, and gap. The pair of repetition positions had a significant effect, on both RT $[F(12,228)=49.77$, $p<.001, M S e=77,455]$ and errors $[F(12,228)=$ $24.61, p<.001, M S e=207.55]$. As shown in Table 2, RT decreased the further to the left the two repetition positions were, and the closer together they were, the lower the RT and errors. Repetition location did not interact with item type on RT $[F(12,228)=1.56, M S e=28,660]$, but did on errors $[F(12,228)=1.96, p<.05$, $M S e=112.98]$; misses tended to be lower on words than on nonwords only when the repeated letters were close together (see Table 2). Distance between repeated letters

Table 1

Experiment 1: Mean Response Time (RT, in msec) and Percentage of Error (PE) Rate for Words and Nonwords by Letter Spacing (Even or Gap) and Presence of Intraword Letter Repetition

\begin{tabular}{lrrrr}
\hline & \multicolumn{4}{c}{ Letter Spacing } \\
\cline { 2 - 5 } Item Type & \multicolumn{2}{c}{ Even } & & Gap \\
\cline { 2 - 5 } \cline { 4 - 5 } & RT & PE & RT & PE \\
Words & 984 & 7.46 & 1099 & 9.00 \\
Nonwords & 1093 & 8.40 & 1195 & 10.00 \\
& & & & \\
Words & 1499 & 2.54 & 1628 & 1.46 \\
Nonwords & 1632 & 1.31 & 1675 & 0.92 \\
\hline
\end{tabular}


Table 2

Experiment 1, Letter Repetition Present: Mean Response Time (RT, in msec) and Percentage of Error (PE) Rate for Words and Nonwords by Serial Positions of Intraword Letter Repetition and Range of Frequency of Occurrence (per Million Words) of Words

\begin{tabular}{|c|c|c|c|c|c|c|}
\hline \multirow{3}{*}{$\begin{array}{c}\text { Repetition } \\
\text { Positions }\end{array}$} & \multirow{3}{*}{$\begin{array}{c}\text { Frequency } \\
\text { Range }\end{array}$} & \multicolumn{4}{|c|}{ Item Type } & \multirow{3}{*}{$\begin{array}{l}\text { Time Savings } \\
\text { for Words }\end{array}$} \\
\hline & & \multicolumn{2}{|c|}{ Words } & \multicolumn{2}{|c|}{ Nonwords } & \\
\hline & & RT & PE & RT & $\mathrm{PE}$ & \\
\hline 1,3 & $11-416$ & 893 & 3.50 & 936 & 7.00 & +43 \\
\hline 1,4 & $18-458$ & 1066 & 6.00 & 1145 & 11.12 & +79 \\
\hline 1,5 & $58-284$ & 1297 & 22.00 & 1417 & 14.00 & +120 \\
\hline 1,6 & $45-373$ & 1298 & 26.50 & 1391 & 27.00 & +93 \\
\hline 2,3 & $11-367$ & 690 & 1.00 & 765 & 1.00 & +75 \\
\hline 2,4 & $43-227$ & 927 & 2.00 & 1106 & 7.00 & +179 \\
\hline 2,5 & $46-359$ & 1180 & 9.50 & 1317 & 11.00 & +137 \\
\hline 2,6 & $43-1016$ & 1354 & 19.00 & 1394 & 21.00 & +40 \\
\hline 3,4 & $50-401$ & 705 & 1.00 & 826 & 4.00 & +121 \\
\hline 3,5 & $10-182$ & 1058 & 4.00 & 1219 & 3.00 & +161 \\
\hline 3,6 & $13-131$ & 1154 & 5.50 & 1197 & 6.50 & +43 \\
\hline 4,5 & $7-492$ & 794 & 1.50 & 950 & 1.50 & +156 \\
\hline 4,6 & $9-83$ & 1122 & 5.50 & 1208 & 5.50 & +86 \\
\hline
\end{tabular}

had little effect on the time savings for words, which were $117,117,86,79$, and $93 \mathrm{msec}$, respectively, for differences in serial position of $1,2,3,4$, and 5 , although, as on errors (misses), the word advantage tended to be larger when the repeated letters were close together. When the RT data were collapsed into the five distance categories, there again was no interaction between distance and item type $(F<1)$.

A third analysis, which was restricted to no-repetition trials, examined the effects of word frequency, which had 13 levels (see Table 3); item type; and gap. Word frequency had a significant effect on RT $[F(12,228)=4.55$, $p<.001, M S e=45,544]$ and errors $[F(12,228)=$ $1.95, p<.05, M S \mathrm{e}=286,988]$, and it interacted with item type on RT $[F(12,228)=2.15, p<.025$, $M S e=44,063]$. However, as shown in Table 3, these are local effects, reflecting peculiarities that are apparently due to the small number of items in each cell (i.e., 10 words or nonwords), and not to trends across the 13 levels of frequency. Mean RT for words was fairly sta- ble at around 1,560 msec, whereas nonword RT showed irregular fluctuations. The 90 -msec time savings for words was quite significant on the no-repetition trials $[F(1,19)$ $=6.71, p<.025, S E=34.90]$, and is all the more impressive considering that there was a higher error rate for words than for nonwords on these trials $[F(1,19)=6.40$, $p<.025, S E=0.350$ ], reflecting a relative bias toward making the other (i.e., repetition present) response.

\section{Discussion}

Contrary to the strong version of the word unitization hypothesis (Pillsbury, 1897), having subjects search for intraword letter repetition, rather than a predesignated target letter, neither eliminated the word-superiority effect nor produced a word frequency disadvantage on norepetition trials. ${ }^{4}$ There was no memory load that might interfere with the encoding of words, and, even though the present task emphasized processing at the letter level, words still were processed as familiar strings, presumably because of the large benefit that that entailed.

Table 3

Experiment 1, No Letter Repetition Present: Mean Response Time (RT, in msec) and Percentage of Error (PE) Rate for Words and Nonwords by Range of Frequency of Occurrence (per Million Words) of Words

\begin{tabular}{|c|c|c|c|c|c|}
\hline \multirow{3}{*}{$\begin{array}{l}\text { Frequency } \\
\text { Range }\end{array}$} & \multicolumn{4}{|c|}{ Item Type } & \multirow{3}{*}{$\begin{array}{l}\text { Time Savings } \\
\text { for Words }\end{array}$} \\
\hline & \multicolumn{2}{|c|}{ Words } & \multicolumn{2}{|c|}{ Nonwords } & \\
\hline & RT & PE & RT & $\mathrm{PE}$ & \\
\hline $386-888$ & 1599 & 4.00 & 1818 & 2.50 & +219 \\
\hline $255-368$ & 1546 & 1.50 & 1607 & .50 & +61 \\
\hline $189-226$ & 1592 & 1.50 & 1631 & .50 & +39 \\
\hline $162-175$ & 1512 & 1.00 & 1568 & 1.00 & +56 \\
\hline $141-159$ & 1553 & 2.00 & 1680 & .50 & +127 \\
\hline $125-141$ & 1579 & 2.00 & 1745 & .00 & +166 \\
\hline $100-116$ & 1523 & 1.50 & 1557 & 1.00 & +34 \\
\hline $89-100$ & 1582 & 1.50 & 1624 & .50 & +42 \\
\hline $74-77$ & 1480 & 1.50 & 1691 & 1.00 & +211 \\
\hline $59-62$ & 1583 & 1.50 & 1601 & .00 & +18 \\
\hline $51-55$ & 1631 & 1.50 & 1705 & 2.50 & +74 \\
\hline $40-41$ & 1597 & 3.00 & 1690 & 2.50 & +93 \\
\hline $22-23$ & 1544 & 3.50 & 1580 & 2.00 & +36 \\
\hline
\end{tabular}


Mean RT was only two-thirds as high on repetition trials as on no-repetition trials, as would be expected if processing were largely self-terminating when repetition was present and exhaustive otherwise. If word unitization interfered with decoding or comparison, then words ought to have fared especially poorly on no-repetition trials, owing to the more extensive (exhaustive) comparison process on those trials than on repetition trials. However, the time savings for words was only slightly (and nonsignificantly) smaller on no-repetition trials $(90 \mathrm{msec}$ ) than on repetition trials $(102 \mathrm{msec})$. In letter search, typical time savings for six-letter common words likewise fall in the 50to 100 -msec range (e.g., Greenberg \& Krueger, 1983; Krueger, 1970, 1982). The fact that the time savings for words was nearly the same for repetition and no-repetition trials indicates that the word advantage was mainly at the initial encoding stage, which presumably was the same for both repetition and no-repetition trials, rather than at the subsequent decoding and comparison stage, which was much longer for no-repetition trials. Previous work likewise indicates that familiarity aids encoding rather than decoding or comparison (Greenberg \& Krueger, 1983; Krueger, 1970, 1982).

On words, subjects had a relative response bias toward detecting letter repetition. Perhaps the compacting of the letters within a more unitary representation increased their perceived similarity, and thus the tendency to report letter repetition. Words especially excelled on errors when the repetition was between nearby letters, which again suggests a compacting of the component letters in the word representation.

Inserting a gap between the third and fourth letters hurt rather than helped performance, especially on words. The gap presumably reduced the word-superiority effect by making the words more difficult to process as familiar objects. If a word-inferiority effect had been found instead, owing to a letter-concealing word unitization process, the gap presumably would have reduced that, too. The gap hurt performance on nonwords as well, perhaps in part because it is more difficult to make comparisons between two separate units than within a single unit. In Experiment 2, two contiguous six-letter strings were used to test whether processing is more difficult when the two units are words rather than nonwords. A compacting of the letters in the word representation (see above) ought to make the comparison of letters between words more difficult.

Some subjects said afterward that in the gap condition, they generally looked at one group of three letters first and then compared it with the other group of three letters, and several subjects said they applied the same strategy in the even-spacing condition. Thus, subjects may not have needed a physical gap in order to treat the sixletter item in a segmented fashion. If so, the gap itself, by increasing the overall distance between letters, could only have hurt performance. In retrospect, it is evident that the total horizontal extent of the six-letter string ought to have been held constant for the gap and even-spacing conditions; that is, the extra space needed for the gap between the third and fourth letters ought to have come from the other interletter spaces.

\section{EXPERIMENT 2}

There was no tendency evident for words to conceal intraword letter repetition in Experiment 1, even though the words seemed to form compact, unitary representations. The decoding and comparison process was equally efficient for words and nonwords, and there was even a word advantage at encoding. Experiment 2 used a multiword task - that is, the detection of letter repetition across two words-rather than a single-word task. In previous studies, comparison of simultaneously presented pairs of words or sequentially redundant pseudowords typically was faster than that of pairs of nonwords (see Krueger's, 1975, review). Silverman (1985) provided evidence that the word advantage in this case is largely due to the fact that words can function as single perceptual units. The word may not deny access to its own letters, as Experiment 1 showed, but its well-demarcated, compacted representation may hinder interword letter comparisons.

To test for a word frequency disadvantage, frequency was varied in Experiment 2 by presenting pairs of common words, rare words, and third-order pseudowords, as well as the corresponding nonwords. In a letter-search task, using the same sets of items, Krueger (1970) found a word frequency advantage; that is, letter search on words was fastest for common words and slowest for third-order pseudowords.

\section{Method}

There were 20 undergraduate subjects. Data were excluded on 2 additional subjects whose errors exceeded $20 \%$. Data from 21 trials with an RT greater than $30 \mathrm{sec}$ or less than $200 \mathrm{msec}$ were discarded prior to data analysis.

The method was the same as in Experiment 1, except for the following changes. There were two rows of six letters, with one row $.4 \mathrm{~cm}$ above the other. The horizontal extent of the two rows was $2.69 \mathrm{~cm}\left(2.20^{\circ}\right)$, whereas the vertical extent was $1.26 \mathrm{~cm}\left(1.03^{\circ}\right)$. The fixation mark, which preceded the display for $.5 \mathrm{sec}$, was centered between the two rows.

Pairs of six-letter items were obtained by randomly sampling items from the appropriate 140-item pool. Six such item pools were devised by Krueger (1970), and a given pool contained common words (occurring 30 or more times per million words), rare words (occurring 1 time per million words), or third-order pseudowords, or the nonwords formed by randomly permuting the letters within each letter position of the corresponding word or pseudoword pool. The third-order pseudowords were constructed so as to reflect the trigram structure of English. (For further details on the item pools, see Krueger, 1970.) Sampling of items was done with replacement, so an item might appear more than once during the session. However, sampling was done in 140 -item passes, so in forming the set of item pairs, no item was tested for inclusion more than once until all other items had been tested once each as well. Thus, particular words typically did not appear more than once or twice in a given row position (top or bottom) during the session. Sampling was done independently for the top and bottom rows. Ninety pairs of items were formed for each of the six types of words or pseudowords (common, rare, and third-order) and corresponding 
nonwords, or 540 pairs in all. On 18 of the 90 pairs, no letter was repeated between the two rows. The other 72 pairs contained repetitions. More pairs were needed for repetition trials in order to have two instances of each of the 36 possible pairwise combinations of matching positions between the two six-letter rows.

The 540 pairs were randomly intermixed and presented in 20 blocks of 27 trials each. Three practice trials preceded each block, and there was an initial practice block, for a total of 630 trials. Four different random orderings of trials and items within pairs were used.

Before the session, the subjects were shown an example of a repeated-letter nonword pair, which contained a letter $J$ in the first position of the top row and in the fourth position of the bottom row, in order to illustrate the difficulty of the task, and the need to search carefully for a letter repetition. The subjects were told that it might work best if they looked at each letter in one row, and compared it with the other row, but that they could make the comparison any way they liked. The subjects were told to look first at the fixation mark, which appeared for $.5 \mathrm{sec}$ at the start of the trial, and then was extinguished when the item pair appeared.

\section{Results}

The main analysis examined the effects of item type, word set (common, rare, or third-order), and repetition (present or absent), all of which are within-subjects factors. As shown in Table 4, compared with no repetition, interword letter repetition greatly decreased RT $[F(1,19)$ $=160.21, p<.001, S E=286.75]$, but increased errors $[F(1,19)=67.97, p<.001, S E=1.334]$. Errors were slightly, but nonsignificantly, higher on words than on nonwords $(F<1)$, whereas RT was lower for words $[F(1,19)=8.64, p<.01, S E=43.30]$, especially when there was no letter repetition $[F(1,19)=4.75, p<.05$, $S E=25.67$, for the item type $\times$ repetition interaction on RT]. In separate analyses, the word advantage on RT was significant both with letter repetition $(71 \mathrm{msec}$; $p<.05)$ and with no letter repetition $(183 \mathrm{msec}$; $p<.01$ ). The word advantage on RT was 80,102 , and $200 \mathrm{msec}$, respectively, for the common word, rare word, and third-order pseudoword sets, which did not differ significantly $(F<1)$. However, on errors, the interaction between item type and word set was significant $[F(2,38)$ $=3.26, p<.05, M S \mathrm{e}=9.82$ ], as was the interaction of item type, word set, and repetition $[F(2,38)=3.54$, $p<.05, M S \mathrm{e}=11.39$ ]. Errors were higher on words than on nonwords on the common word set, especially when letter repetition was present, but slightly lower on

Table 4

Experiment 2: Mean Response Time (RT, in msec) and Percentage of Error (PE) Rate for Words and Nonwords by Word Set and Presence of Interword Letter Repetition

\begin{tabular}{|c|c|c|c|c|c|c|}
\hline \multirow[b]{3}{*}{ Pair Type } & \multicolumn{6}{|c|}{ Word Set } \\
\hline & \multicolumn{2}{|c|}{ Common } & \multicolumn{2}{|c|}{ Rare } & \multicolumn{2}{|c|}{ Third-order } \\
\hline & RT & $\mathrm{PE}$ & RT & PE & RT & PE \\
\hline \multicolumn{7}{|c|}{ Letter Repetition Present } \\
\hline Words & 3188 & 13.59 & 3245 & 11.61 & 3280 & 12.91 \\
\hline Nonwords & 3279 & 10.75 & 3253 & 13.43 & 3395 & 11.85 \\
\hline \multicolumn{7}{|c|}{ No Letter Repetition Present } \\
\hline Words & 6882 & 1.70 & 6790 & 1.68 & 6762 & 0.83 \\
\hline Nonwords & 6951 & 0.85 & 6987 & 0.83 & 7046 & 2.24 \\
\hline
\end{tabular}

words than on nonwords on the rare word and third-order pseudoword sets. The word advantage on errors was $-1.84 \%,+.48 \%$, and $+.18 \%$, respectively, for the common word, rare word, and third-order pseudoword sets. When each word set was analyzed separately, only the word advantage on RT for the third-order pseudoword set was significant $[F(1,19)=6.86, p<.025, S E=$ 76.21], as was the word disadvantage on errors for the common word set $[F(1,19)=4.32, p \approx .05, S E=0.888]$.

In a second analysis, which was restricted to letter repetition trials, the trials were classified by the difference in the serial position of the repeated letter between the two rows, item type, and word set. Although it peaked at a difference in position of 3 , the word advantage on RT generally decreased, but not significantly so, as the difference in position increased $[F(5,95)=1.70$, $M S e=366,912$, for the item type $\times$ difference in position interaction on RT]. The time savings for words were $157,60,19,220,-17$, and $-192 \mathrm{msec}$, respectively, for a difference of $0,1,2,3,4$, and 5 positions.

\section{Discussion}

A word-superiority effect was found in Experiment 2; mean RT was lower on words than on nonwords, and errors did not differ significantly. However, a word frequency disadvantage also was found; as word frequency increased, errors on words increased significantly compared with errors on nonwords and the time savings for words decreased, but not significantly so. The third-order pseudowords accounted for over half of the word superiority on RT, and, when each word set was analyzed separately, only the third-order pseudowords produced a significant word superiority on RT. Thus, the wordsuperiority effect was primarily an orthographic regularity effect. By contrast, Krueger (1970), using the same materials, found a word frequency advantage on RT for letter search.

When questioned afterward, subjects said that they used the following comparison strategies on about one-third of the trials each: (1) a single letter from one row, usually the top one, was compared against the other row; (2) groups of letters were compared between rows; and (3) the two rows were compared as wholes. Several subjects said that they tended to look less at the individual letters and more at the string as a whole on words than on nonwords, which some subjects said they liked, presumably because it speeded the process, but other subjects said they disliked, presumably because it led to more misses on common words. Several subjects said they based their comparisons of words on sound, which caused problems, some said, because several different letters might have the same sound. If the sound factor was more important on common words, which are more familiar and presumably more pronounceable, that could explain why misses were more frequent on them than on the corresponding nonwords. The third-order pseudowords, as meaningless strings, may have been processed more like nonwords than words, but their familiar local (i.e., bi- 
gram, trigram) structure nevertheless aided processing considerably.

Mean RT was about half as large on letter repetition as on no-repetition trials, owing presumably to selfterminating processing. Unlike Experiment 1, the time savings for words likewise declined, and was about half as large on repetition as on no-repetition trials. Thus, the relative time savings for words remained nearly constant; it was $2.16 \%$ on repetition trials, and $2.62 \%$ on norepetition trials. However, the latter pattern, which indicates that familiarity aided mainly the comparison process, was evident only on rare words and third-order pseudowords, and may reflect a greater tendency to compare those items as letter groups rather than as wholes. Encoding remained the locus of the word advantage on RT for common words; as in Experiment 1, the time savings for common words was only slightly (and nonsignificantly) larger on repetition trials $(90 \mathrm{msec})$ than on norepetition trials $(69 \mathrm{msec})$. The high miss rate on common words could be due to insufficient processing (i.e., a speed-accuracy tradeoff), but more likely it reflects greater difficulty at the comparison stage. In sum, local (bigram, trigram) familiarity generally aided processing, but high familiarity of the overall string (i.e., common words) led to a decline or reversal in the word advantage, especially on errors. Thus, although the word representation does not deny access to its letter components, and still is encoded faster, it makes the comparison of letters between words more difficult.

\section{GENERAL DISCUSSION}

No previous study has provided clear-cut support for the strong version of the word unitization hypothesis (Pillsbury, 1897), according to which the recognition of the word always or necessarily hinders subsequent access to its constituent letters. Letter detection typically is better in single words than in nonwords (Henderson, 1975; Krueger, 1975). The present study tested whether the word advantage at the initial encoding stage (Greenberg \& Krueger, 1983; Krueger, 1970, 1982) might conceal or mask a word disadvantage at the subsequent decoding and comparison stage. With unpracticed subjects and under difficult conditions, the time savings for words decreases when the number of target letters increases, thereby increasing the number of memory comparisons (Greenberg \& Krueger, 1983; Krueger, 1969). However, this may have been due not to word unitization, but to less efficient word encoding, owing to the increased memory load.

In Experiment 1, the decoding and comparison operation was magnified, but without thereby increasing the memory load, by having subjects search for the presence of letter repetition within a word or nonword. The task emphasized processing at the letter level, but words were still processed as familiar strings, not as collections of letters, because the typical word-superiority effect, involving about a 100 -msec time savings for a six-letter word, was found. The word advantage was only slightly smaller on no-repetition trials, which involved many more letter comparisons than did the letter repetition trials. Thus, words aided encoding and did little or no harm to decoding or comparison. The familiar word seemingly forms a compact representation with, rather than against (Pillsbury, 1897), its own letters, because the word advantage on misses was larger when the repeated letters were closer together (Table 2). Placing a gap in the middle of the sixletter string hurt performance in Experiment 1, owing apparently to the difficulty in comparing letters across separate units.

In Experiment 2, subjects had to compare letters across two unrelated words or nonwords, and, although familiarity generally aided processing, there was a word frequency disadvantage on errors. Thus, component letters of highly familiar, common words are easily decoded and compared within a word (Experiment 1), but not between two unrelated words (Experiment 2). Experiment 2 differed from Experiment 1, too, in that the locus of the familiarity effect for rare words and third-order pseudowords was at the decoding and comparison stage, consistent with Johnson's (1986) model. Subjects apparently performed best when they compared only a few letters at a time between words or nonwords, and the familiar local units in the rare words and third-order pseudowords made that comparison much easier. The representation of the common word did not deny access to its letter components (Experiment 1), but, perhaps due to its greater unitization with its own letters, made those letter components more difficult to compare with the letters of other, unrelated words. (If the two words in Experiment 2 had been related, and thus had formed a familiar multiword representation, there presumably would have been no deficit evident on common words.)

However, the occasional difficulties that highly familiar common words suffer at decoding or comparison ought not to overshadow the great benefits that all words obtain at encoding. The word frequency disadvantage in Experiment 2, after all, was nonsignificant on RT and only just significant on errors $(p<.05)$. By contrast, the word-superiority effect on RT was quite significant in Experiment $2(p<.01)$, as it was in Experiment 1 $(p<.001)$. Thus, words much more readily aid than hurt letter detection. Only through rather extraordinary measures (i.e., use of the interword letter detection task in Experiment 2), was any diminution in that net aid revealed, and the persistence of (or hope for) some net aid apparently induced subjects to process even common words as familiar strings in Experiment 2. Thus, contrary to Pillsbury (1897), the letter is not inevitably lost in the violent rush of word recognition, and it generally gains more than it loses in its association with the word. Likewise, the word had a definite impact, even though the present task, with its heavy focus on letter comparisons, might easily have induced subjects to process the strings exclusively at the letter level. Thus, letter and word coexist quite well with each other. 


\section{REFERENCES}

Abramovici, S. (1983). Errors in proofreading: Evidence for syntactic control of letter processing? Memory \& Cognition, 11, 258-261.

Besner, D., DavelaAr, E., Alcott, D., \& Parry, P. (1984). Wholistic reading of alphabetic print: Evidence from the FDM and the FBI. In L. Henderson (Ed.), Orthographies and reading: Perspectives from cognitive psychology, neuropsychology, and linguistics (pp. 121-135). Hillsdale, NJ: Erlbaum.

Corcoran, D. W. J. (1966). An acoustic factor in letter cancellation. Nature, 210, 658.

Drewnowski, A. \& HeALY, A. F. (1977). Detection errors on the and and: Evidence for reading units larger than the word. Memory \& $\mathrm{Cog}$ nition, 5, 636-647.

GreenberG, S. N., \& KRUEGer, L. E. (1983). Effect of letter orientation and sequential redundancy on the speed of letter search. Memory \& Cognition, 11, 181-191.

HABER, R. N., Schindler, R. M. (1981). Error in proofreading: Evidence of syntactic control of letter processing? Journal of Experimental Psychology: Human Perception \& Performance, 7, 573-579.

Healy, A. F. (1976). Detection errors on the word the: Evidence for reading units larger than letters. Journal of Experimental Psychology: Human Perception \& Performance, 2, 235-242.

Healy, A. F. (1980). Proofreading errors on the word the: New evidence on reading units. Journal of Experimental Psychology: Human Perception \& Performance, 6, 45-57.

Healy, A. F., \& Drewnowski, A. (1983). Investigating the boundaries of reading units: Letter detection in misspelled words. Journal of Experimental Psychology: Human Perception \& Performance, 9, 413-426.

Healy, A. F., Oliver, W. L., \& McNamara, T. P. (1987). Detecting letters in continuous text: Effects of display size. Joumal of $E x-$ perimental Psychology: Human Perception \& Performance, 13 , 279-290.

Henderson, L. (1975). Do words conceal their component letters? A critique of Johnson (1975) on the visual perception of words. Journal of Verbal Learning \& Verbal Behavior, 14, 648-650.

JoHNSON, N. F. (1977). A pattern-unit model of word identification. In D. LaBerge \& S. J. Samuels (Eds.), Basic processes in reading: Perception and comprehension (pp. 91-125). Hillsdale, NJ: Erlbaum.

JoHNSON, N. F. (1981). Integration processes in word recognition. In O. J. L. Tzeng \& H. Singer (Eds.), Perception of print: Reading research in experimental psychology (pp. 29-63). Hillsdale, NJ: Erlbaum.

JoHnson, N. F. (1986). On looking at letters within words: Do we "see" them in memory? Journal of Memory \& Language, 25, 558-570.

KRUEGER, L. E. (1969). Search time in a redundant visual display. Unpublished doctoral disseration, Harvard University, Cambridge, MA

KRUEGER, L. E. (1970). Search time in a redundant visual display. Journal of Experimental Psychology, 83, 391-399.

KRUEGER, L. E. (1975). Familiarity effects in visual information processing. Psychological Bulletin, 82, 949-974.

KRUEGER, L. E. (1982). A word-superiority effect with print and braille characters. Perception \& Psychophysics, 31, 345-352.

Krueger, L. E., \&hapiro, R. G. (1980). Repeating the target neither speeds nor slows its detection: Evidence for independent channels in letter processing. Perception \& Psychophysics, 28, 68-76.

KuČERA, H., \& FranCIS, W. N. (1967). Computational analysis of present-day American English. Providence, RI: Brown University Press.

LAWRY, J. A. (1980). The interfering effect of word perception on letter identification. Perception \& Psychophysics, 28, 577-588.

LEVY, B. A. (1983). Proofreading familiar text: Constraints on visual processing. Memory \& Cognition, 11, 1-12.

Levy, B. A., \& BegiN, J. (1984). Proofreading familiar text: Allocating resources to perceptual and conceptual processes. Memory \& Cognition, 12, 621-632.
Levy, B. A., Newell, S., Snyder, J., \& Timmins, K. (1986). Processing changes across reading encounters. Journal of Experimental Psychology: Leaming, Memory, \& Cognition, 12, 467-478.

O'HARA, W. P. (1980). Evidence in support of word unitization. Perception \& Psychophysics, 27, 390-402.

O'HARA, W., ERIKSEN, C. W. (1979). Word unitization examined using an interference paradigm. Bulletin of the Psychonomic Society, 14, 81-84

Pillsbury, W. B. (1897). A study in apperception. American Journal of Psychology, 8, 315-393.

Proctor, J. D., \& Healy, A. F. (1985). A secondary-task analysis of a word familiarity effect. Joumal of Experimental Psychology: Human Perception \& Performance, 11, 286-303.

SCHINDLER, R. M. (1978). The effect of prose context on visual search for letters. Memory \& Cognition, 6, 124-130.

Silverman, W. P. (1976). Can "words" be processed as integrated units? Perception \& Psychophysics, 20, 143-152.

Silverman, W. P. (1977). Are visually presented one-syllable words integral stimuli? Bulletin of the Psychonomic Society, 9, 103-105.

Silverman, W. P. (1985). Two types of word superiority effects in a speeded matching task. Memory \& Cognition, 13, 50-56.

\section{NOTES}

1. In addition to factors directly pertaining to word unitization (task difficulty, task instructions, and use of function words), Greenberg and Krueger (1983, Table 5) cited other factors that might account for the failure of Healy and Schindler (1978) (Drewnowski \& Healy, 1977; Healy, 1976, 1980) to find familiarity effects, such as Healy's use of consonant targets and Healy's and Schindler's uses of lowercase letters. However, in recent, unpublished work, I have found the time savings for words over nonwords in letter search to be as large with consonant targets as with vowel targets, and as large with lowercase letters as with uppercase letters. Thus, the latter factors do not seem critical, and the present study, which used uppercase letters and used both repeated consonants and repeated vowels, ought to be sensitive to any loss or reversal in the word advantage due to the use of the repetition-detection task.

2. Advocates of the strong version might counter that after the word is recognized, subjects need merely redirect their attention to the component letters in the visual display in order to identify them. However, that would still predict a word disadvantage, since nonwords seemingly would be encoded directly into their letter components, and thus would require no such change in attention. Nor is such a redirection of attention away from the word consistent with the word advantage in letter detection that is typically found when single words or nonwords are presented (Henderson, 1975; Krueger, 1975).

3 . Actually, the word, as well as its constituent letters, may be overshadowed by the multiword text. Just as not all component letters need be identified in order for a word to be identified, so, too, not all component words need be identified for a meaningful phrase or sentence to be identified (Drewnowski \& Healy, 1977), and some redundant words may be regularly skipped over entirely (Corcoran, 1966). Abramovici (1983) and Haber and Schindler (1981), contrary to Healy (1980), found that misspellings are less well detected in function words than in content words when word shape, length, and frequency of the target items are better equated across the syntactic classes (also see Healy \& Drewnowski, 1983). They argued that the contextual predictability of function words leads subjects to give less attention to their analysis, thus making both constituent and deviant letters less available for detection. Contrary to the attentional hypothesis, however, Healy (1976) found that even in a nonsense passage of scrambled words in which the was no longer predictable from its context, more $t$ s were missed in the than in other words. With reading for comprehension serving as the primary task, Proctor and Healy (1985) consistently obtained a word-inferiority effect and word frequency disadvantage on a secondary task when the latter involved letter detection, but not when it involved the detection of aberrant closely spaced (double) dots in the underscoring of the pas- 
sage. If lack of attention to the familiar words were the culprit, it presumably would have hurt performance on both secondary tasks, not only on letter detection. However, double-dot detection may have depended in part on peripheral vision, and that may have made it less sensitive to the occurrence of reduced attention on particular words in the passage.

4. If frequency had been varied over a wider range, as in Experiment 2 , a word frequency advantage might well have been found (Krue- ger, 1970). The words used on no-repetition trials in Experiment 1 were all quite common, occurring 22 times or more per million words (Table 3).

(Manuscript received April 24, 1987; revision accepted for publication April 18, 1988.) 